\title{
Pretreatment with phenoxybenzamine attenuates the radial artery's vasoconstrictor response to $\alpha$-adrenergic stimuli
}

Joel S. Corvera, MD

Cullen D. Morris, MD

Jason M. Budde, MD

Daniel A. Velez, MD

John D. Puskas, MD

Omar M. Lattouf, MD

William A. Cooper, MD

Robert A. Guyton, MD

Jakob Vinten-Johansen, PhD
From the Cardiothoracic Research Laboratory, Division of Cardiothoracic Surgery, Carlyle Fraser Heart Center at Crawford Long Hospital, Emory University School of Medicine, Atlanta, Ga.

Received for publication Nov 19, 2002; revisions requested $\mathrm{Feb}$ 10, 2003; revisions received April 16, 2003; accepted for publication April 24, 2003.

Address for reprints: Jakob Vinten-Johansen, $\mathrm{PhD}$, Cardiothoracic Research Laboratory, Carlyle Fraser Heart Center, 550 Peachtree St, NE, Atlanta, GA 30308-2225 (E-mail: jvinten@emory.edu).

J Thorac Cardiovasc Surg 2003;126: 1549-54

Copyright $\odot 2003$ by The American Association for Thoracic Surgery

$0022-5223 / 2003 \$ 30.00+0$

doi:10.1067/S0022-5223(03)01190-5
Background: Although the radial artery bypass conduit has excellent intermediateterm patency, it has a proclivity to vasospasm. We tested the hypothesis that brief pretreatment of a radial artery graft with the irreversible adrenergic antagonist phenoxybenzamine attenuates the vasoconstrictor response to the vasopressors phenylephrine and norepinephrine compared with the currently used papaverine/ lidocaine.

Methods: Segments of human radial artery grafts were obtained after a 30-minute intraoperative pretreatment with a solution containing $20 \mathrm{~mL}$ of heparinized blood, $0.4 \mathrm{~mL}$ of papaverine $(30 \mathrm{mg} / \mathrm{mL})$, and $1.6 \mathrm{~mL}$ of lidocaine $(1 \%)$. The segments were transported to the laboratory and placed into a bath containing Krebs-Henseleit solution and 10,100 , or $1000 \mu \mathrm{mol} / \mathrm{L}$ phenoxybenzamine or vehicle. The segments were tested in organ chambers for contractile responses to increasing concentrations of phenylephrine and norepinephrine $(0.5-15 \mu \mathrm{mol} / \mathrm{L})$.

Results: Contractile responses to $15 \mu \mathrm{mol} / \mathrm{L}$ phenylephrine in control radial artery segments averaged $44.2 \% \pm 9.1 \%$ of the maximal contractile response to 30 $\mathrm{mmol} / \mathrm{L} \mathrm{KCl}$. Papaverine/lidocaine modestly attenuated contraction to $15 \mu \mathrm{mol} / \mathrm{L}$ phenylephrine $(32.1 \% \pm 5.9 \% ; P=.22)$, but $1000 \mu \mathrm{mol} / \mathrm{L}$ phenoxybenzamine completely abolished radial artery contraction $(-7.2 \% \pm 4.4 \% ; P<.001)$. The effect of 10 and $100 \mu \mathrm{mol} / \mathrm{L}$ phenoxybenzamine on attenuating vasocontraction was intermediate between $1000 \mu \mathrm{mol} / \mathrm{L}$ phenoxybenzamine and papaverine/lidocaine. Responses to $15 \mu \mathrm{mol} / \mathrm{L}$ norepinephrine in control radial artery segments averaged $54.7 \% \pm 7.5 \%$ of maximal contraction to $30 \mathrm{mmol} / \mathrm{L} \mathrm{KCl}$. Papaverine/lidocaine modestly attenuated the contraction response of radial artery segments $(35.6 \% \pm$ $5.1 \% ; P=.04)$. In contrast, $1000 \mu \mathrm{mol} / \mathrm{L}$ phenoxybenzamine showed the greatest attenuation of norepinephrine-induced contraction $(-10.5 \% \pm 2.0 \% ; P<.001)$.

Conclusions: A brief pretreatment of the human radial artery bypass conduit with $1000 \mu \mathrm{mol} / \mathrm{L}$ phenoxybenzamine completely attenuates the vasoconstrictor responses to the widely used vasopressors norepinephrine and phenylephrine. Papaverine/lidocaine alone did not block vasoconstriction to these $\alpha$-adrenergic agonists. 


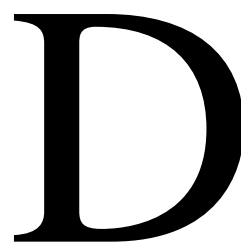

issatisfied with the pathologic changes noted in saphenous vein bypass grafts in coronary artery bypass surgery, Carpentier and colleagues, ${ }^{1}$ in 1973 , advocated the use of the radial artery (RA) as a bypass conduit in the aorta-coronary position. They noted excellent handling qualities and length. Two years later, enthusiasm for the RA as a bypass conduit waned because of the reported high frequency of graft occlusion that was attributed to vasospasm. ${ }^{2}$ By 1976, the use of RA grafts was completely abandoned. However, Acar and colleagues ${ }^{3}$ revisited the use of the RA after several patients in Carpentier and associates' original series were found to have patent, disease-free RA grafts after 15 years. In a subsequent series of patients, Acar and colleagues found 1- and 5-year patency rates to be $92 \%$ and $83 \%$, respectively. ${ }^{4}$ Others have corroborated these excellent short-term and intermediate-term patency rates of the RA conduit. ${ }^{5-10}$ Important to the revival of the RA as a bypass conduit was the "no-touch" technique of harvesting a pedicled RA; avoiding endothelial damage by refraining from using intraluminal probes; using vasodilators such as papaverine, lidocaine, and nitroglycerin in soaking solutions; and administering parenteral calcium channel blockers after surgery. However, the use of the RA is not universally accepted, possibly because of reports of vasospasm and myocardial hypoperfusion in the immediate postoperative period despite the use of intraoperative papaverine and postoperative calcium channel blockers. ${ }^{11,12}$

In 2000, Taggart and colleagues ${ }^{13}$ reported that phenoxybenzamine (PBZ), a noncompetitive and irreversible $\alpha$-adrenergic receptor antagonist, blocked the contraction of the ex vivo human RA in response to epinephrine. Taggart and associates pretreated the RA with a soaking solution containing $100 \mathrm{mg}$ of PBZ in $50 \mathrm{~mL}$ of heparinized blood (5.9 $\mathrm{mmol} / \mathrm{L}$ PBZ) and tested the RA segments within 1 hour of treatment. Subsequently, Velez and colleagues ${ }^{14}$ demonstrated that in canine RA a much lower concentration of PBZ ( $1 \mu \mathrm{mol} / \mathrm{L})$ blocked the contractile response to increasing concentrations of norepinephrine (NE) and phenylephrine (PE) at 2, 24, and 48 hours after treatment. $\mathrm{NE}$ and $\mathrm{PE}$ are most often used for hemodynamic support in the postoperative period and are used during off-pump coronary bypass operations to treat hypotension caused by cardiac elevation and manipulation to visualize posterior and lateral target vessels. In addition, Velez and associates ${ }^{14}$ demonstrated that $1 \mu \mathrm{mol} / \mathrm{L}$ papaverine, a vasodilator most often given intraluminally after the RA graft is harvested, did not attenuate the vasospasm associated with $\alpha$-adrenergic stimuli. In this study, we determined the optimal concentration of PBZ in a buffered solution used to soak and pretreat RA segments harvested from patients undergoing coronary artery bypass graft surgery. The RA graft is typically har- vested with the surrounding musculofascial pedicle, which may impede exposure of the vessel to agents designed to attenuate vasoconstriction, such as papaverine/lidocaine and PBZ. Therefore, we also tested the hypothesis that performing an incision through the musculofascial tissue (fasciotomy) would allow greater exposure of the graft to papaverine/lidocaine and PBZ and thereby increase the efficacy of these agents.

\section{Materials and Methods Surgical Preparation}

RA segments were obtained from unused portions of RA conduits of patients having elective coronary artery bypass grafting with or without cardiopulmonary bypass at the Crawford Long Hospital of Emory University. A modified Allen's test was performed to assess the adequacy of preoperative collateral circulation to the hand. ${ }^{15}$ The RA was harvested with its pedicle containing the venae comitantes, perivascular fat, and areolar tissue (no fasciotomy) by using a no-touch technique. Branches of the RA were ligated with vascular clips. A subset of the RA grafts had the musculofascial tissue incised (with fasciotomy) to expose the areolar tissue adjacent to the graft. The RA was then placed in a solution containing $20 \mathrm{~mL}$ of heparinized blood, $1.6 \mathrm{~mL}$ of $1 \%$ lidocaine, and $0.4 \mathrm{~mL}$ of papaverine $(30 \mathrm{mg} / \mathrm{mL})$ for approximately 30 minutes at room temperature. The RA graft was flushed intraluminally with the blood/papaverine/lidocaine solution at the beginning and at 15 minutes of the soaking period to ensure exposure of the intimal PBZ. Before its placement in the aortocoronary position, a small segment of the RA was obtained and immediately placed in Krebs-Henseleit $(\mathrm{K}-\mathrm{H})$ buffer $(118 \mathrm{mmol} / \mathrm{L}$ $\mathrm{NaCl}, 4.7 \mathrm{mmol} / \mathrm{L} \mathrm{KCl}, 1.2 \mathrm{mmol} / \mathrm{L} \quad \mathrm{KH}_{2} \mathrm{PO}_{4}, 1.2 \mathrm{mmol} / \mathrm{L}$ $\mathrm{MgSO}_{4}, 2.5 \mathrm{mmol} / \mathrm{L} \mathrm{CaCl}{ }_{2}, 12.5 \mathrm{mmol} / \mathrm{L} \mathrm{NaHCO}_{3}$, and 10 $\mathrm{mmol} / \mathrm{L}$ glucose) at $4^{\circ} \mathrm{C}, \mathrm{pH} 7.4$ and transported to our Cardiothoracic Research Laboratory.

\section{Experimental Protocol}

The RA segment with or without fasciotomy was placed into K-H buffer (pH 7.4) at $25^{\circ} \mathrm{C}$ with 10,100 , or $1000 \mu \mathrm{mol} / \mathrm{L} \mathrm{PBZ} \mathrm{or}$ vehicle. The RA was flushed intraluminally twice with this solution, once at the beginning and once at the end of a 30-minute incubation period, which approximates the time between RA harvest and placement in the aorta-coronary position. In addition, control RA segments were obtained before intraoperative pretreatment of the conduit with the papaverine/lidocaine solution and received no other treatment. The segments were prepared for placement in organ bath chambers by carefully skeletonizing them in cold K-H buffer and cutting them into rings 3 to $5 \mathrm{~mm}$ in length. The rings were then mounted on stainless-steel hooks, connected to FT-03 force displacement transducers, and placed into Radnoti organ chambers (Radnoti Glass, Monrovia, Calif) containing $7 \mathrm{~mL}$ of oxygenated (95\% oxygen $/ 5 \%$ carbon dioxide) $\mathrm{K}-\mathrm{H}$ buffer at $37^{\circ} \mathrm{C}$ and $\mathrm{pH} 7.4$. Indomethacin $(10 \mu \mathrm{mol} / \mathrm{L})$ was added to the buffer to block responses to endogenous prostanoids. The rings were stabilized for 1 hour with frequent buffer changes and set to a predetermined tension that allowed $75 \%$ of maximal contraction to $30 \mathrm{mmol} / \mathrm{L} \mathrm{KCl}$. 
The rings were then incubated with increasing concentrations of PE (0.5-15 $\mu \mathrm{mol} / \mathrm{L})$ or NE $(0.5-15 \mu \mathrm{mol} / \mathrm{L})$. After the highest concentration of $\alpha$-adrenergic agent was achieved, $30 \mathrm{mmol} / \mathrm{L} \mathrm{KCl}$ was added to the bath to quantify the maximal non-receptormediated constriction. In randomly selected vessels, the integrity of the RA endothelium was also tested for its receptor-dependent relaxation response to incremental concentrations of acetylcholine (ACh), a stimulator of nitric oxide synthase. The rings were precontracted with the thromboxane $\mathrm{A}_{2}$ mimetic U46619 (1.4 $\mathrm{nmol} / \mathrm{L})$ and then exposed to increasing concentrations of ACh (1 $\mathrm{nmol} / \mathrm{L}$ to $11.7 \mu \mathrm{mol} / \mathrm{L}$ ) in the presence of $10 \mu \mathrm{mol} / \mathrm{L}$ indomethacin.

The changes in isometric force were quantified by using an analog-to-digital converter sampling at $2 \mathrm{~Hz}$. The responses were analyzed with a Windows-based videographics program (SPECTRUM; Wake Forest University, Winston-Salem, NC). The force of contraction elicited by exposure to increasing concentrations of PE and NE was expressed as a percentage of the maximal contraction generated by $\mathrm{KCl}$ in each ring. The degree of relaxation after exposure to $\mathrm{ACh}$ was expressed as the percentage tension reduction from the maximal force of contraction obtained from U46619.

\section{Chemicals}

The following drugs were purchased from the Sigma Chemical Company (St Louis, Mo): acetylcholine chloride, $\mathrm{KCl}, \mathrm{NE}$, Lphenylephrine hydrochloride, K-H buffer, calcium chloride, and sodium bicarbonate. PBZ hydrochloride (Dibenzyline) was a gift from SmithKline Beecham Pharmaceuticals (Collegeville, Pa).

\section{Statistical Analysis}

Data were analyzed for significance by using a 1-way analysis of variance comparing the control, papaverine/lidocaine, and PBZ groups at each concentration of $\mathrm{NE}$ and $\mathrm{PE}$. If a significant difference between groups was assigned by analysis of variance, a post hoc Student-Newman-Keuls test was applied to locate the source of differences. All data are reported as mean \pm SEM.

\section{Results}

PE caused a concentration-dependent vasoconstriction in control RA ( $\mathrm{n}=10)$ segments; the contraction achieved at the maximal concentration of PE $(15 \mu \mathrm{mol} / \mathrm{L})$ averaged $44.2 \% \pm 9.1 \%$ of the $\mathrm{KCl}$ response (Figure 1). Pretreatment of the RA in papaverine/lidocaine solution $(n=32)$ did not significantly attenuate the concentration-dependent contraction responses to PE. Contraction at the highest concentration of PE was reduced by only $27 \%$ of control vessels $(32.1 \% \pm 5.9 \% ; P=.22)$. In contrast, PBZ in addition to papaverine/lidocaine attenuated the vasoconstriction to $\mathrm{PE}$ in a dose-dependent manner (Figure 1). At the highest concentration of PE used $(15 \mu \mathrm{mol} / \mathrm{L})$, the vasoconstriction response was attenuated by $63 \%$ of control at $10 \mu \mathrm{mol} / \mathrm{L}$ PBZ ( $\mathrm{n}=23 ; 16.5 \% \pm 4.3 \% ; P=.02)$, by $80 \%$ of control at $100 \mu \mathrm{mol} / \mathrm{L} \mathrm{PBZ}(\mathrm{n}=28 ; 8.7 \% \pm 5.1 \% ; P=.003)$, and by $116 \%$ of control at $1000 \mu \mathrm{mol} / \mathrm{L} \mathrm{PBZ} \mathrm{(n=22;-7.2 \%}$ $\pm 4.4 \% ; P<.001)$.

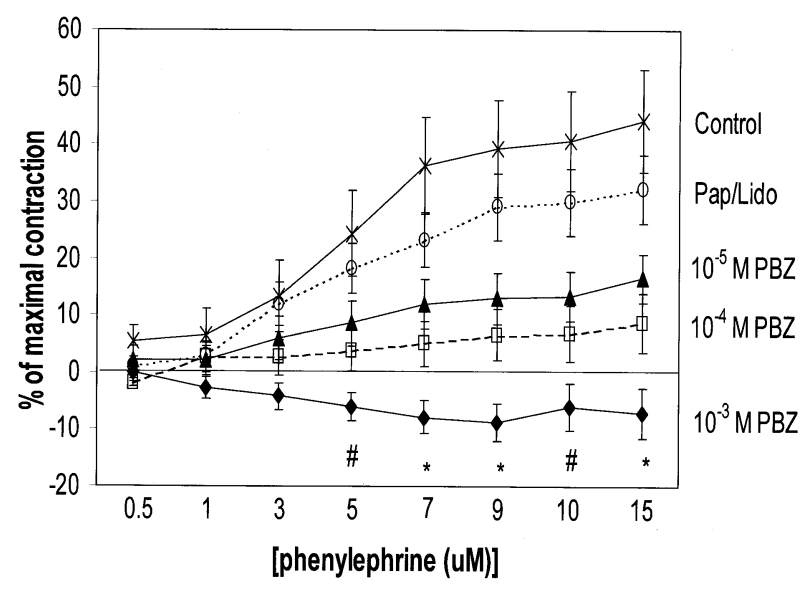

Figure 1. Radial artery vasocontraction responses to increasing concentrations of phenylephrine, with or without pretreatment with 3 different concentrations of phenoxybenzamine (PBZ). PBZ attenuates vasocontraction to phenylephrine in a concentrationdependent manner. PBZ, Phenoxybenzamine pretreatment; Pap/ Lido, papaverine/lidocaine pretreatment; control, no pretreatment. ${ }^{*} P<.05,10^{-3} \mathrm{~mol} / \mathrm{L} \mathrm{PBZ}$ versus $10^{-4}$ and $10^{-5} \mathrm{~mol} / \mathrm{L} \mathrm{PBZ}$, Pap/Lido, and control. \#P $<.05,10^{-3} \mathrm{~mol} / \mathrm{L}$ PBZ versus $10^{-5} \mathrm{~mol} / \mathrm{L}$ PBZ, Pap/Lido, and control.

Incremental concentrations of NE also caused progressive vasoconstriction in control human RA segments $(\mathrm{n}=$ $11 ; 54.7 \% \pm 7.5 \%$ of maximal contraction to $30 \mathrm{mmol} / \mathrm{L}$ $\mathrm{KCl}$; Figure 2). Soaking the RA in a combination of papaverine/lidocaine blood solution modestly but significantly attenuated this vasoconstriction response to $15 \mu \mathrm{mol} / \mathrm{L} \mathrm{NE}$ $(\mathrm{n}=36 ; 35.6 \% \pm 5.1 \% ; P=.04)$. Although PBZ at 10 $\mu \mathrm{mol} / \mathrm{L}(\mathrm{n}=26)$ inhibited constriction to concentrations of $\mathrm{NE}$ greater than $7 \mu \mathrm{mol} / \mathrm{L}, \mathrm{PBZ}$ at $1000 \mu \mathrm{mol} / \mathrm{L}(\mathrm{n}=27)$ completely inhibited constrictor responses across all concentrations of NE (Figure 2). In summary, $1000 \mu \mathrm{mol} / \mathrm{L}$ PBZ added to papaverine/lidocaine completely inhibits the vasoconstriction induced by PE and NE.

The potential for fasciotomy at the time of RA harvest to facilitate exposure of the vessel to PBZ pretreatment was investigated. At the highest concentration of PE tested (15 $\mu \mathrm{mol} / \mathrm{L})$, there was no significant difference between RA segments with fasciotomy and without fasciotomy with either papaverine/lidocaine treatment $(n=19$ with fasciotomy; $\mathrm{n}=13$ without fasciotomy) or PBZ treatment $(1000 \mu \mathrm{mol} / \mathrm{L} ; \mathrm{n}=12$ with fasciotomy; $\mathrm{n}=10$ without fasciotomy; Figure 3). Similarly, there was no benefit to fasciotomy with either papaverine/lidocaine pretreatment (n $=22$ with fasciotomy; $\mathrm{n}=14$ without fasciotomy) or PBZ pretreatment $(\mathrm{n}=17$ with fasciotomy; $\mathrm{n}=10$ without fasciotomy) when vasoconstriction was achieved by $\mathrm{NE}$ (Figure 4).

RA endothelial function was tested by quantifying the relaxation response to increasing concentrations of $\mathrm{ACh}$, a 


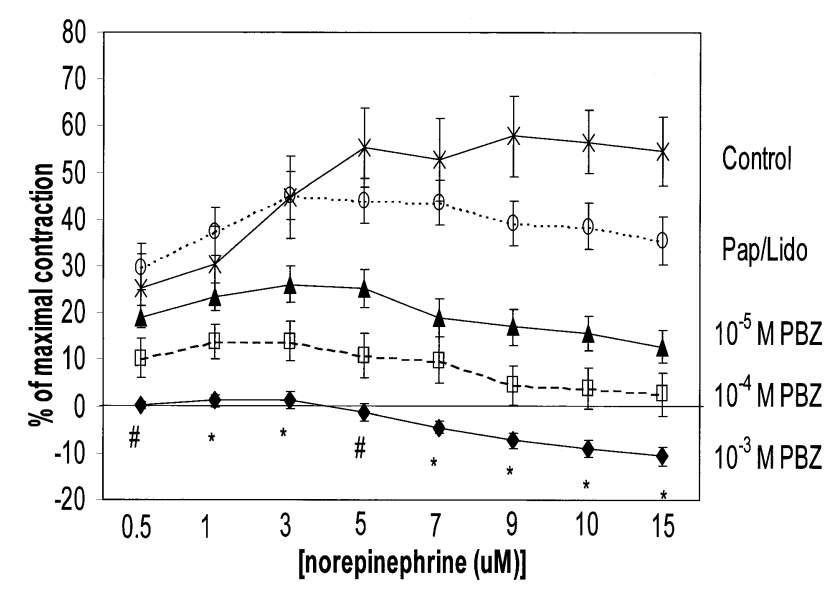

Figure 2. Radial artery vasocontraction responses to increasing concentrations of norepinephrine, with or without pretreatment with 3 different concentrations of phenoxybenzamine (PBZ). PBZ attenuates vasocontraction to norepinephrine in a concentrationdependent manner. PBZ, Phenoxybenzamine pretreatment; Pap/ Lido, papaverine/lidocaine pretreatment; control, no pretreatment. ${ }^{*} P<.05,10^{-3} \mathrm{~mol} / \mathrm{L} \mathrm{PBZ}$ versus $10^{-4}$ and $10^{-5} \mathrm{~mol} / \mathrm{L} \mathrm{PBZ}$, Pap/Lido, and control. \#P $<.05,10^{-3} \mathrm{~mol} / \mathrm{L}$ PBZ versus $10^{-5} \mathrm{~mol} / \mathrm{L}$ PBZ, Pap/Lido, and control.

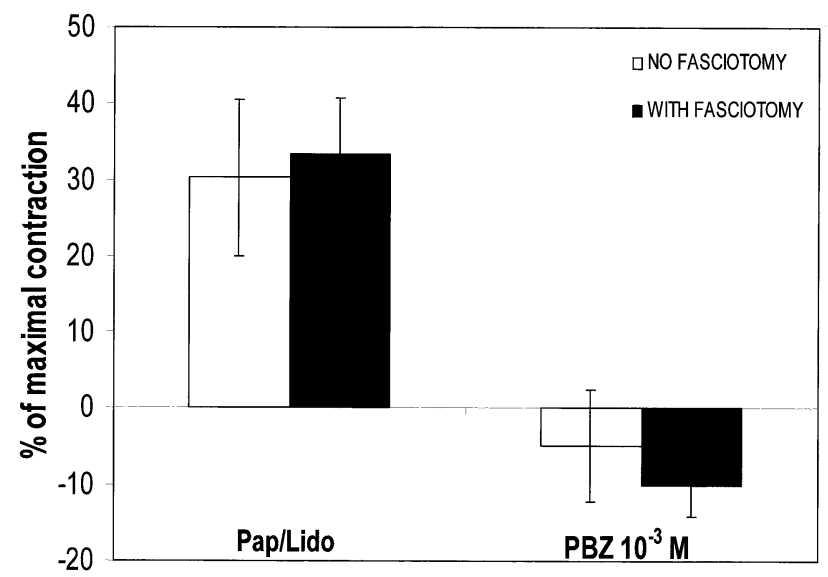

Figure 3. Radial artery vasocontraction responses to $15 \mu \mathrm{mol} / \mathrm{L}$ phenylephrine, with and without fasciotomy after treatment with $10^{-3} \mathrm{~mol} / \mathrm{L}$ phenoxybenzamine or papaverine/lidocaine. PBZ, Phenoxybenzamine pretreatment; Pap/Lido, papaverine/lidocaine pretreatment. There were no significant differences between fasciotomy and no fasciotomy in the efficacy of PBZ or papaverine/lidocaine against $15 \mu \mathrm{mol} / \mathrm{L}$ phenylephrine.

receptor-dependent stimulator of nitric oxide synthase. All RA segments had similar precontraction tensions generated by treatment with U46619 (PBZ-treated with fasciotomy, $14.4 \pm 1.9 \mathrm{~g}$ of tension; PBZ-treated without fasciotomy, $15.0 \pm 1.8 \mathrm{~g}$; papaverine/lidocaine with fasciotomy, $13.1 \pm$ $1.4 \mathrm{~g}$; papaverine/lidocaine without fasciotomy, $14.9 \pm$

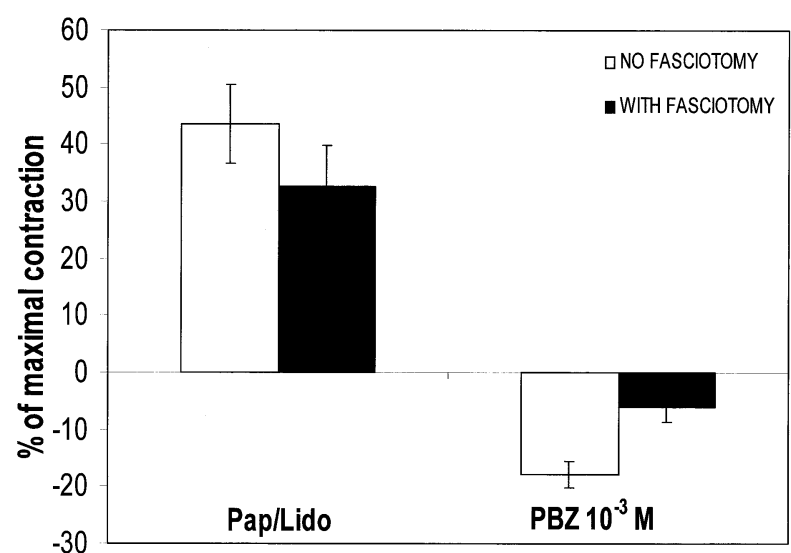

Figure 4. Radial artery vasocontraction responses to $15 \mu \mathrm{mol} / \mathrm{L}$ norepinephrine, with and without fasciotomy after treatment with $10^{-3} \mathrm{~mol} / \mathrm{L}$ phenoxybenzamine or papaverine/lidocaine. $P B Z$, Phenoxybenzamine pretreatment; Pap/Lido, papaverine/lidocaine pretreatment. There were no significant differences between fasciotomy and no fasciotomy in the efficacy of PBZ or papaverine/lidocaine against $15 \mu \mathrm{mol} / \mathrm{L}$ norepinephrine.

$1.6 \mathrm{~g} ; P=.79)$. Endothelial function was not significantly attenuated in RA segments in which a fasciotomy was performed (Figure 5). In the segments treated with papaverine/lidocaine, those without fasciotomy $(\mathrm{n}=10)$ demonstrated an $84.6 \% \pm 6.8 \%$ relaxation response to $12 \mu \mathrm{mol} / \mathrm{L}$ $\mathrm{ACh}$, and those with fasciotomy $(\mathrm{n}=17)$ demonstrated an $80.7 \% \pm 5.7 \%$ relaxation response $(P=$ not significant $)$. In the segments treated with $1000 \mu \mathrm{mol} / \mathrm{L} \mathrm{PBZ}$ in addition to intraoperative papaverine/lidocaine, those without fasciotomy $(\mathrm{n}=9)$ demonstrated an $81.0 \% \pm 11.8 \%$ relaxation response to $12 \mu \mathrm{mol} / \mathrm{L}$ ACh, suggesting no additional impairment of endothelial function compared with RA segments treated with papaverine/lidocaine alone. Those that had fasciotomy and were treated with PBZ/papaverine/lidocaine $(\mathrm{n}=8)$ showed a trend toward reduced endothelial function, averaging a $67.6 \%$ plusmn; $5.2 \%$ relaxation response to ACh $(P=.33$ compared with segments treated with PBZ/papaverine/lidocaine without fasciotomy; unpaired Student $t$ test).

\section{Discussion}

This study showed that PBZ significantly attenuates the human RA constriction response to the clinically used vasopressors $\mathrm{NE}$ and $\mathrm{PE}$ in a dose-dependent manner. At a concentration of $1000 \mu \mathrm{mol} / \mathrm{L}, \mathrm{PBZ}$ completely blocks vasocontraction to concentrations of $\alpha$-adrenergic agents that are typically used during off-pump surgery to treat intraoperative hypotension and that are used after surgery to sustain systemic blood pressure. PBZ at concentrations of 100 and $10 \mu \mathrm{mol} / \mathrm{L}$ has some efficacy in attenuating RA vasocontraction; however, these concentrations do not completely 
block the response to $\mathrm{NE}$ and PE compared with 1000 $\mu \mathrm{mol} / \mathrm{L} \mathrm{PBZ}$, which completely blocked vasoconstriction but also unmasked the vasodilatation component of the mixed $\alpha$ - and $\beta$-adrenergic agent NE. Furthermore, performing an incision in the fascial plane to expose the graft to topical vasodilators does not increase the efficacy of either PBZ or papaverine/lidocaine. A pedicled harvest of the RA to avoid graft trauma, combined with pretreatment of the RA with $1000 \mu \mathrm{mol} / \mathrm{L}$ PBZ to block vasospasm from $\alpha$-adrenergic stimuli, may be important in preventing RA graft vasospasm and its complications, especially in the early postoperative period.

The optimal concentration at which PBZ completely abolished adrenergically induced vasoconstriction was 1000-fold greater than that reported for canine RA by Velez and colleagues. ${ }^{14}$ There is likely a species difference in response to $\alpha$-adrenergic agents between human beings and dogs that may be related to the density of adrenergic receptors. In addition, the RAs arteries were skeletonized in the study by Velez and colleagues, and this may facilitate exposure to PBZ. It was thought that the presence of the soft tissue pedicle surrounding the human RA graft impedes contact of PBZ with the graft. However, in this study, increasing the exposure of the graft via fasciotomy did not change the efficacy of PBZ or papaverine/lidocaine. Complete skeletonization of the RA graft was not performed, as advocated by Taggart and colleagues ${ }^{16}$ because skeletonization is contrary to the no-touch technique to avoid conduit trauma and may encourage vasospasm.

The optimal concentration used in this study is 6-fold less than that used by Taggart and colleagues. ${ }^{16}$ Concentrations of PBZ higher than $1000 \mu \mathrm{mol} / \mathrm{L}$ are unnecessary because $1000 \mu \mathrm{mol} / \mathrm{L}$ PBZ effectively blocks vasoconstriction by $\alpha$-adrenergic agents. The formulation of PBZ used by both this study and that of Taggart and colleagues is a highly acidic solution composed of ethanol, hydrochloric acid, and propylene glycol that must be properly buffered to avoid endothelial or other cellular injury. The $\mathrm{pH}$ of Taggart and associates' blood/PBZ solution was not reported. However, Taggart and colleagues ${ }^{13}$ and Dipp and colleagues ${ }^{17}$ demonstrated full endothelial function with a blood-based solution of greater than $1000 \mu \mathrm{mol} / \mathrm{L}$ PBZ. In this study, PBZ at a concentration of $1000 \mu \mathrm{mol} / \mathrm{L}$ in a buffered crystalloid solution did not cause endothelial dysfunction. However, papaverine alone has been shown to cause a decrease in endothelium-dependent relaxation by ACh in internal thoracic arteries and RAs. ${ }^{17-20} \mathrm{We}$ observed that the use of papaverine/lidocaine in RA segments attenuated the endothelium-dependent relaxation response to ACh by $15 \%$ to $20 \%$ (data not shown). The use of papaverine in RA grafting is deleterious to the endothelium of the conduit; however, a properly buffered blood- or crystalloid-based

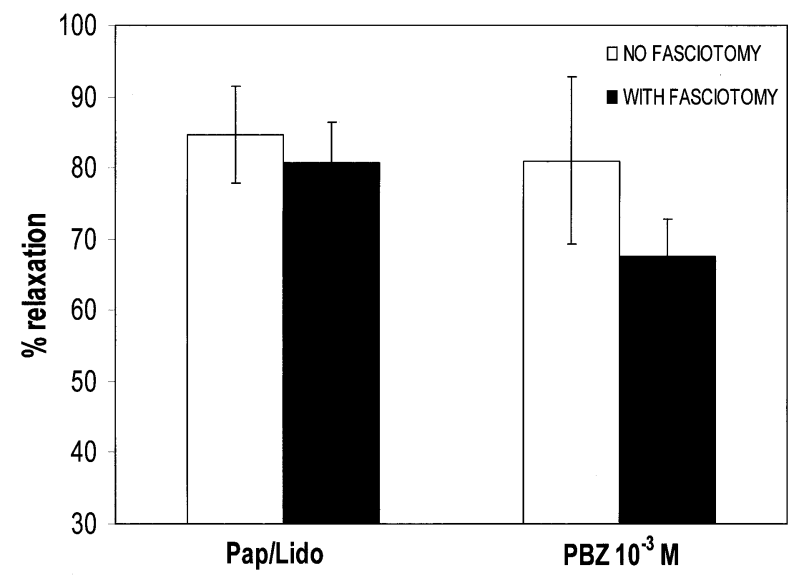

Figure 5. Radial artery endothelial function expressed as percentage relaxation to $12 \mu \mathrm{mol} / \mathrm{L}$ acetylcholine, with and without fasciotomy after treatment with $10^{-3} \mathrm{~mol} / \mathrm{L}$ phenoxybenzamine or papaverine/lidocaine. $P B Z$, Phenoxybenzamine pretreatment; Pap/Lido, papaverine/lidocaine pretreatment. There were no significant differences between treatments or fasciotomy.

solution of $1000 \mu \mathrm{mol} / \mathrm{L}$ PBZ does not cause endothelial dysfunction.

External exposure alone via simple immersion of the graft in a PBZ solution may not be optimally effective. Because the vasa vasorum of the RA does not penetrate the muscular vessel media, ${ }^{21-23}$ we also flushed the RA conduit intraluminally to maximize exposure of the graft to the agents.

In summary, pretreatment of the RA conduit with PBZ attenuates the vasoconstrictor response to the widely used vasopressors NE and PE. The efficacy of $1000 \mu \mathrm{mol} / \mathrm{L}$ PBZ is not enhanced by increasing external exposure of the graft via an incision in the soft tissue pedicle (fasciotomy); however, gentle intraluminal flushing is important for delivering the drug to the muscular vessel media. RA vasospasm is effectively blocked ex vivo by carefully preserving the soft tissue pedicle protecting the graft and pretreating the conduit with PBZ. Endothelial function is preserved with the use of PBZ. Therefore, we recommend the no-touch technique of RA harvesting and brief pretreatment of the RA graft with $1000 \mu \mathrm{mol} / \mathrm{L}$ PBZ.

We thank Laurie Berley for her assistance in preparing this manuscript. We also acknowledge the assistance of Susan McCall and Linda Robertson for their assistance in coordinating the project.

\section{References}

1. Carpentier A, Guermonprez JL, Deloche A, Frechette C, DuBost C. The aorta-to-coronary radial artery bypass graft: a technique avoiding pathologic changes in grafts. Ann Thorac Surg. 1973;16:111-21.

2. Carpentier A. Discussion of Geha AS, Krone RJ, McCormick JR, Baue 
AE. Selection of coronary bypass: anatomic, physiological, and angiographic considerations of vein and mammary artery grafts. $J$ Thorac Cardiovasc Surg. 1975;70:414-31.

3. Acar C, Jebara VA, Portoghese M, Beyssen B, Pagny JY, Grare P, et al. Revival of the radial artery for coronary artery bypass grafting. Ann Thorac Surg. 1992;54:652-60.

4. Acar C, Ramsheyi A, Pagny J-Y, Jebara V, Barrier P, Fabiani J-N, et al. The radial artery for coronary artery bypass grafting: clinical and angiographic results at five years. J Thorac Cardiovasc Surg. 1998; 116:981-9.

5. Califiore AM, Di Giammarco G, Luciani N, Maddestra N, Di Nardo E, Angelini R. Composite arterial conduits for a wider arterial myocardial revascularization. Ann Thorac Surg. 1994;58:185-90.

6. Dietl C, Benoit C. Radial artery grafts for coronary artery bypass grafting. Ann Thorac Surg. 1995;60:102-10.

7. Brodman RF, Frame R, Camacho M, Hu E, Chen A, Hollinger I. Routine use of unilateral and bilateral radial arteries for coronary artery bypass surgery. J Am Coll Cardiol. 1996;28:959-63.

8. da Costa FDA, da Costa IA, Poffo R, Abuchaim D, Gaspar R, Garcia $\mathrm{L}$, et al. Myocardial revascularization with the radial artery: a clinical and angiographic study. Ann Thorac Surg. 1996;62:475-80.

9. Manasse E, Sperti G, Suma H, Canosa C, Kol A, Martinelli L, et al. Use of the radial artery for myocardial revascularization. Ann Thorac Surg. 1996;62:1076-83.

10. Bahn A, Gupta V, Choudhary SK, Sharma R, Singh B, Aggarwal R, et al. Radial artery in CABG: could the early results be comparable to internal mammary artery graft? Ann Thorac Surg. 1999;67:1631-6.

11. Apostolidou IA, Skubas NJ, Despotis GJ, Kallinteri E, Hogue CW, Lappas DG, et al. Occurrence of myocardial ischemia immediately after coronary revascularization using radial artery conduits. $J$ Cardiothorac Vasc Anesth. 2001;15:433-8.

12. Gabe ED, Figal JC, Wisner JN, Laguens R. Radial artery graft vasospasm. Eur J Cardiothorac Surg. 2001;19:102-4.
13. Taggart DP, Dipp M, Mussa S, Nye PCG. Phenoxybenzamine prevents spasm in radial artery conduits for coronary artery bypass grafting. J Thorac Cardiovasc Surg. 2000;120:815-7.

14. Velez DA, Morris CD, Muraki S, Budde JM, Otto RN, Zhao Z-Q, et al. Brief pretreatment of radial artery conduits with phenoxybenzamine prevents vasoconstriction long term. Ann Thorac Surg. 2001;72:197784.

15. Johnson WH III, Cromartie RS III, Arrants JE, Wuamett JD, Holt JB. Simplified method for candidate selection for radial artery harvesting. Ann Thorac Surg. 1998;65:1167.

16. Taggart DP, Mathur MN, Ahmad I. Skeletonization of the radial artery: advantages over the pedicled technique. Ann Thorac Surg. 2001;72:298-9.

17. Dipp MA, Nye PCG, Taggart DP. Phenoxybenzamine is more effective and less harmful than papaverine in prevention of radial artery vasospasm. Eur J Cardiothorac Surg. 2001;19:482-6.

18. Cooper GJ, Wilkinson GAL, Angelini GD. Overcoming perioperative spasm of the internal mammary artery: which is the best vasodilator? J Thorac Cardiovasc Surg. 1992;104:465-8.

19. Cooper GJ, Gillot T, Parry EA, Kennedy A, Wilkinson GA. Papaverine injures the endothelium of the internal mammary artery. Cardiovasc Surg. 1995;3:553-5.

20. He G-W. Verapamil plus nitroglycerin solution maximally preserves endothelial function of the radial artery: comparison with papaverine solution. J Thorac Cardiovasc Surg. 1998;115:1321-7.

21. He G-W. Arterial grafts for coronary artery bypass grafting: biological characteristics, functional classification, and clinical choice. Ann Thorac Surg. 1999;67:277-84.

22. van Son JAM, Smedts F, Vincent JG, van Lier HJJ, Kubat K. Comparative anatomic studies of various arterial conduits for myocardial revascularization. J Thorac Cardiovasc Surg. 1990;99:703-7.

23. Chester AH, Amrani M, Borland JAA. Vascular biology of the radial artery. Curr Opin Cardiol. 1998;13:447-52. 